\title{
CONTEÚDO DO PROVIMENTO DEFINIDO PELA IDENTIFICAÇÃO DO DIREITO FUNDAMENTAL EM DEBATE: UMA FALSA PREMISSA
}

CONTENT OF THE REMEDIES DEFINED BY THE IDENTIFICATION OF THE FUNDAMENTAL RIGHT AT STAKE: A FALSE PREMISE

CONTENIDO DE LA DECISIÓN DEFINIDA POR LA IDENTIFICACIÓN DEL DERECHO FUNDAMENTAL EN DEBATE: UNA FALSA PREMISA

\section{Vanice Regina Lírio do Valle ${ }^{1}$}

Resumo: A abordagem tradicional sobre a relação entre direitos e provimento jurisdicional que o assegura refere a uma relação causal e dedutiva que se inicia no primeiro, predeterminando o último. A subvalorização da operação de delimitação de conteúdo do provimento é vista como modo de prevenir uma contaminação de preocupações operacionais associadas à enunciação da ordem. Este artigo demonstra a inadequação de um entendimento que situa nos direitos a inteira definição da resposta judicial para uma violação reclamada quando se cuida de direitos socioeconômicos. A indeterminação do conteúdo, atributo desejável dos direitos sociais, requer mais da adjudicação do que uma operação dedutiva. Baseado numa revisão bibliográfica,

1 Visiting Fellow no Human Rights Program - Harvard Law School; Pós-doutorado junto à EBAPE - FGV/Rio; Doutorado na Universidade Gama Filho. Professora Permanente no Programa de Pós-Graduação em Direito da UNESA, Rio de Janeiro, RJ, Brasil. E-mail: vanicevalle@gmail.com. 
o artigo aplica o método crítico-analítico para demonstrar a inadequação da posição centrada nos direitos na busca do objetivo da efetividade dos direitos socioeconômicos. Juízes, quando decidindo, interferem numa discussão em curso quanto ao seu conteúdo, o que pode não se revelar favorável à efetividade.

Palavras-chave: direitos socioeconômicos - provimento jurisdicional - relação causal - efetividade

Abstract: The traditional approach to the rights-remedies relationship refers to a causal-deductive relationship that starts in the first and predetermines the latter. Devaluating remedies is seen as way to protect rights from a contamination coming from grass-rooted concerns associated with remedies. This paper demonstrates the inadequacy and insufficiency of an understanding that sets, in the rights, the whole definition of the judicial response to a claimed violation, especially when it comes to socioeconomic rights. The lack of determination of content of rights, a desirable feature when it comes do socioeconomic rights, will require more from adjudication than a simple deductive operation. Based on a literature review, the article applies the analytical and critical method, to demonstrate the inadequacy of a rights-centered understanding when it comes to enforcing socioeconomic rights. Judges, when making decisions, are involved in a discussion of their content, which may not always prove to be pro-enforcement.

Keywords: socioeconomic rights - remedies - causal relationship - effectiveness

Resumen: El abordaje tradicional sobre la relación entre derechos y la decisión jurisdiccional que los asegura se refiere a una relación causal y deductiva que se inicia en el primero, predeterminando el último. La subvaloración de la operación de delimitación del contenido de la decisión es vista como un modo de prevenir una contaminación de preocupaciones operacionales asociadas a la enunciación de la orden. Este artículo demuestra la inadecuación de un entendimiento que sitúa en los derechos la entera definición de la respuesta judicial para una violación reclama- 
da cuando se cuida de derechos socioeconómicos. La indeterminación del contenido, atributo deseable de los derechos sociales, requiere más de la adjudicación que una operación deductiva. Basado en una revisión bibliográfica, el artículo aplica el método crítico-analítico para demostrar la inadecuación de la posición centrada en los derechos en la búsqueda del objetivo de la efectividad de los derechos socioeconómicos. Los Jueces, cuando deciden, interfieren en una discusión en curso en relación a su contenido, lo que puede revelarse no favorable a la efectividad.

Palabras clave: Derechos socioeconómicos; Decisión jurisdiccional; Relación causal; Efectividad.

INTRODUÇÃO

tradução do ideário de direitos humanos para a linguagem do direito
stricto sensu pode ser justificada estrategicamente como meio de
robustecer esta mesma proposta. No terreno pantanoso dos direitos socioeconômicos, a ampliação da sua sindicabilidade abrirá as portas para o controle judicial $^{2}$ - e isto pode ajudar no avanço da agenda de desenvolvimento inserida nas raízes do discurso dos direitos humanos. ${ }^{3}$

O objetivo do presente trabalho é demonstrar que a adjudicação de direitos socioeconômicos raramente é resultado de uma aplicação objetiva de uma providência jurisdicional corretiva predeterminada pelo conteúdo do próprio direito. A necessária relação entre direito (violado) e resposta jurisdicional (preventiva, restauradora ou compensadora) nunca é meramente dedutiva ou formal. Esta aproximação supostamente causal, alinhada com a velha máxima de que a cada direito corresponde uma ação, não encontra perfeita correspondência com a realidade. A hipótese, de outro lado, é de que a suposta relação causal e 2 Para uma análise da presença e justiciabilidade dos direitos socioeconômicos nas constituições ao redor do mundo, JUNG, Courtney, HIRSCHL, Ran e ROSEVEAR, Evan, Economic and Social Rights in National Constitutions. American Journal of Comparative Law, Ann Arbor, Michigan, v. 62, n. 4, p. 1043-1094, 2014.

3 A opção estratégica apesar de disseminada - a militância de direitos humanos utilizandose da judicialização como um instrumento alternativo de impulsionamento da agenda política - ainda é uma controvérsia. Para uma síntese dos possíveis resultados negativos da judicialização, KENNEDY, D., International Human Rights Movement: Part of the Problem?, Harvard Human Rights Journal, Cambridge, v. 15, p. 101-125, 2002. 
objetiva empobrece a noção de provimento jurisdicional, seu papel na resolução do conflito e a efetividade do comando ali expendido; consequentemente, fragilizar o objetivo de empoderamento dos direitos socioeconômicos.

Na realidade, a correlação entre direito e o provimento jurisdicional que o tutela deveria ser compreendida como de interferências recíprocas; como uma construção empreendida pelo juízo, orientada em tese, a conferir o máximo de eficácia possível ao direito debatido, observados os limites específicos do processo judicial em curso. O reconhecimento desta verdadeira simbiose evidencia o fato de que limitações processuais podem induzir a oposição de óbices à sindicabilidade em si do direito, ou mesmo reduzir seu conteúdo, tudo tendo em conta a preservação da autoridade da decisão judicial. Este tipo de estratégia enfraquece a ideia de que a jurisdição possa ser um caminho suplementar de empoderamento dos direitos socioeconômicos, eis que a prestação jurisdicional com este perfil, em vez de promover o fortalecimento desses mesmos direitos, demonstra-se regressiva. ${ }^{4}$

Muitas serão as consequências desta simples afirmação de ausência de uma relação causal e dedutiva entre direito e resposta judicial a ele associada. Primeiro, a proposição restaura a ideia de que a transformação social integre um ciclo permanente, traduzido por uma pauta de direitos a proteger, cujo alcance pode se ver oxigenado pelo debate judicial. A adjudicação não pode ser compreendida como um fenômeno isolado, dissociado de uma reivindicação social prévia e divorciado de uma aferição prospectiva dos seus reais efeitos. Mesmo num regime de não vinculação a precedentes, uma abordagem inaugural em feitos envolvendo direitos socioeconômicos tende à multiplicação, amplificando a repercussão de uma ordem judicial percebida inicialmente como circunscrita a um caso isolado.

A segunda consequência de reconhecer-se a existência de interferência mútua entre direito e o provimento jurisdicional que o assegura é evidenciar que a adjudicação não é uma atividade objetiva, politicamente neutra. Isso se tem por especialmente relevante no campo dos direitos humanos, em que 4 Apontando para estes mesmos riscos no sistema constitucional Sul-africano, LIEBENBERG, S. Socio-economic rights: adjudication under a transformative constitution, Cape Town: Juta and Company Ltd, 2010, p. 141. 
inclusive a condição de right-owner pode ser, em si, discutível. Esta ausência de neutralidade reclama não apenas maior ônus argumentativo, mas também maior clareza em relação ao tipo de justiça que será priorizada na decisão: uma adjudicação tradutora de justiça compensatória restrita ao autor, ou uma maior preocupação com um critério de justiça de caráter distributivo, que tenha por objetivo o impulsionamento do processo de transformação como um todo.

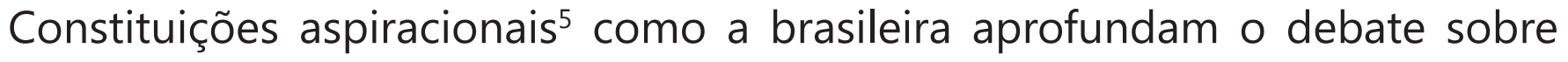
o papel do judiciário na promoção de transformação social. Maximalistas nos seus objetivos, direcionamento demonstrado numa concepção positivada de direitos e princípios; estas constituições convidam ao ativismo judicial ${ }^{6}$, vez que o aprofundamento do processo de transformação é exigido pelo Texto Fundamental, e frequentemente não implementado pelos braços legislativo e executivo, pelo menos não com a velocidade ou amplitude devida. 0 mito dos direitos ${ }^{7}$, fundado numa suposta relação direta entre litigiosidade, direitos, resposta judicial e promoção por meio destes, da transformação social, vai incentivar a disputa social $^{8}$, e o judiciário irá sofrer também o ônus deste realinhamento no que toca às expectativas institucionais, agora a ele direcionadas.

A dificuldade está em que a incorporação de direitos socioeconômicos numa constituição nacional normalmente acontece mediante formulações genéricas, deixando espaço aberto para decisões supervenientes no que toca a elementos substantivos destes mesmos direitos, a saber, seus limites, as políticas públicas que devem ser associadas à sua implementação, e ainda qual seja a racionalidade distributiva incidente na espécie. Esta abertura pode ser creditada

5 SCHEPPELE, Kim Lane. Aspirational and Aversive Constitutionalism: The Case for Studying Cross-constitutional Influence Through Negative Models, International Journal of Constitutional Law, New York, v. 1, n.2, 2003, p. 299, indicando que no constitucionalismo aspiracional, os decisores constitucionais estão comprometidos com metas que pretendem atingir, adotando fundamentalmente uma visão prospectiva.

6 GARCÍA-VILLEGAS, Mauricio. Law as Hope: Constitutions, Courts, and Social Change in Latin America, Wisconsin International Law Journal, Madison, v. 20, n. 2, 2001-2002, p. 356.

7 SCHEINGOLD, Stuart A., The politics of rights: lawyers, public policy and political change, USA: Yale University Press, 1974, p. 5.

8 Para uma análise comparativa da curva incremental de litigância na discussão de direito à saúde, citam-se MAESTAD, Otlae RAKNE Lise e FERRAZ, Octavio L. Motta, Assessing the Impact of Health Rights Litigation: a Comparative Analysis of Argentina, Brazil, Colombia, Costa Rica, India, and South Africa, in YAMIN, A.; GLOPPEN, S. Litigating health rights. Can courts bring more justice to health? Cambridge: Harvard University Press, 2011, p. 273. 
à crença na importância de uma enunciação que acolha futuras contingências sociais capazes de ampliar ou restringir aqueles mesmos direitos ${ }^{9}$, realinhando as prioridades. Vagueza na formulação de direitos pode também ser resultado de ausência de consenso durante o processo constituinte. ${ }^{10}$ Independente das possíveis explicações, os direitos socioeconômicos usualmente chegam aos textos constitucionais em termos pouco claros.

A ideia de que para cada direito violado corresponda uma resposta adjudicativa específica, fruto de uma relação causal, é reforçada pelo princípio do non liquet, segundo o qual uma decisão deva ser proferida, não obstante a vagueza da moldura legal. Uma presunção atitudinal contra qualquer vazio entre um direito de sede constitucional (como o são os sociais), e a prestação jurisdicional que o assegura também é um elemento de pressão por uma decisão judicial dotada de um conteúdo concreto. ${ }^{11}$ Esse cenário complexo conduz a uma deliberação judicial que não é resultado direto da aplicação de um direito previamente definido na lei ou em critérios regulados. Algumas vezes essa decisão irá refletir uma aproximação subjetiva do caso, apoiado frequentemente na ideologia ou na percepção pessoal do julgador quanto ao problema.

Sentenças podem influenciar a definição de conteúdo de direitos sociais mas o terreno da política pública pode contra-atacar, demonstrando falhas neste mesmo entendimento, ou ainda consequências indesejadas. Essa demonstração

9 LIU, Goodwin. Rethinking Constitutional Welfare Rights, Stanford Law Review, Stanford, v. 61, n. 2, Winter 2010, p. 209.

10 SUNSTEIN, Cass. Acordos constitucionais sem teorias constitucionais. Revista de Direito Administrativo, v. 246, Rio de Janeiro, 2007, p.79-94, argumentando que cláusulas constitucionais vagas podem ser meios de expressar o máximo consenso possível alcançado no processo constituinte; DIXON, Rosalind; GINSBURG, Tom. Deciding Not to Decide: Deferral in Constitutional Design. International Journal of Constitutional Law, New York, v. 9, n. 3-4, outubro 2011, p. 636-672, explorando as ferramentas por meio das quais os designers da constituição deferem a certas questões constitucionais para o futuro, adotando linguagem constitucional vaga e através de linguagens específicas nas quais delegam o detalhamento aos futuros legisladores). Na literatura brasileira, VIEIRA, Oscar Vilhena, Do compromisso maximizador ao constitucionalismo resiliente. In: DIMOULIS, D. et al. Resiliência constitucional: compromisso maximizador, consensualismo política e desenvolvimento gradual, São Paulo: Direito GV, 2013, p. 18-24.

11 Supremacia constitucional exige maximização dos efeitos concretos das cláusulas constitucionais, consequentemente, a não correspondência entre as aspirações e os denominados direitos e os mecanismo para a sua garantia é considerada uma falha (JEFFRIES JR.; John C. The Right-Remedy Gap in Constitutional Law, Yale Law Journal, New Haven, v. 109, n.1, p. 87-89). 
argumentativa pode uma vez mais deitar reflexos no entendimento judicial, reformatando o resultado adjudicativo, numa construção dialógica de um direito que nunca pretendeu, desde o seu início, ser absoluto e imutável. ${ }^{12}$ Essa interrelação que se tem por ocultada pelo imaginário mesmo dos profissionais do direito, que preferem a representação pacificadora de que a enunciação pura e simples do direito, a tudo dá resposta.

A assunção de uma relação não dedutiva entre direitos e o provimento adjudicativo que dá resposta à sua alegada violação vai abrir oportunidade para meditar acerca do experimentalismo judicial como uma possibilidade ${ }^{13}$ - e não como um erro ou desvio no que toca à adjudicação. Práticas dialógicas, diferimento dos efeitos temporais da sentença, fixação de metas a serem alcançadas - e não de padrões de conduta a serem observados -; todas essas são alternativas na definição do conteúdo do provimento. Admitir o controle judicial de efeitos sub-ótimos alcançados por políticas públicas requer o reconhecimento de que o projeto constitucional de transformação não é concretizado simplesmente pela atribuição de eficácia imediata a direitos sociais.

Este artigo se desenvolve da seguinte maneira: depois das considerações iniciais deduzidas nesta Parte 1, a Parte 2 é dedicada à apresentação e à crítica a duas aproximações que reduzem a relevância da resposta adjudicativa na compreensão da atividade jurisdicional como meio de empoderamento dos compromissos e valores constitucionais. A primeira destas aproximações essencialismo dos direitos - supervaloriza o reconhecimento e a delimitação dos componentes constitucionais do direito. A segunda aproximação - o tailoring principle - proclama uma necessária e estreita correspondência entre violação a direitos e resposta jurisdicional, o que significa dizer que o primeiro define 0

12 YOUNG, Katharine. Freedom, Want and Economic and Social Rights: Frame and Law. Mariland Journal of International Law, Maryland, v. 24, N. 1, 2009, p. 184, propondo que direitos socioeconômicos devem ser tidos não só como um método de incrementar a pressão sobre os tomadores de decisão, mas também como uma moldura ao discurso mantido nas contestações políticas ao exercício da justiça distributiae).

13 VALLE, Vanice Regina Lírio. O papel da adjudicação como mecanismo social de composição de conflitos. In.: CÂMARA, Alexandre Freitas; PIRES, Adilson; MARÇAL, Thais (Org.). Estudos de Direito Administrativo em Homenagem ao Professor Jessé Torres Pereira Junior. Belo Horizonte: Editora Fórum, 2016, p. 371-387, explorando a necessidade, em questões de alta complexidade, de abrir-se a prestação jurisdicional a um grau de experimentalismo que permita sua eventual reconfiguração, à vista dos resultados dela decorrentes. 
conteúdo da prestação adjudicativa. ${ }^{14}$ Esta suposta relação causal entre direitos e provimento jurisdicional assumida por ambas as perspectivas resulta em negligenciar os atributos necessários à adequada execução da sentença no ciclo de enforcement e atualização do conteúdo dos direitos sociais. Nenhuma das perspectivas atende de maneira adequada ao propósito de incremento na sua efetividade. A Parte 3 aponta as inconsistências nas referidas abordagens, bem como os efeitos deletérios no que toca à efetividade dos direitos sociais. Em conclusão, aponta-se uma pauta de reflexão para uma reconfiguração da relação estabelecida entre direitos sociais e provimentos jurisdicionais assecuratórios de sua efetividade. O objetivo é incrementar a efetiva contribuição institucional que a intervenção judicial possa trazer ao desafio de implementação do projeto de transformação traduzido pela Constituição de 1988.

\section{SECUNDARIZANDO A CONSTRUÇÃO DO CONTEÚDO DA} ORDEM JUDICIAL

A dimensão da empreitada de definição do conteúdo dos direitos sociais e dos mecanismos próprios ao seu fortalecimento operacional através da jurisdição parece ser diretamente informada por dois possíveis atributos de um sistema jurídico: o caráter sintético ou analítico do Texto Fundamental e a escolha entre um modelo de civil law ou de comon law.

Constituições sintéticas vão levar a um esforço interpretativo mais amplo na decisão se o direito " $x$ " ou " $y$ " é protegido pela Lei Fundamental. Direitos em espécie serão reconhecidos como manifestação de valores ou princípios constitucionais como no cenário norte-americano, em que os direitos civis se tem no mais das vezes extraídos da cláusula de isonomia ou do due process. Ainda assim se tem aberta a questão relacionada à promoção de sua efetividade no plano concreto - se isso deve ser confiado às Cortes e em que termos.

Constituições analíticas, de outro lado, aludindo normalmente a um direito " $x$ " ou " $y$ ", oferecem uma primeira impressão de que direitos sociais se tenham 14 FISS, Owen M. The Supreme Court, Term. Foreword: The Forms of Justice, 1979. Harvard Law Review, Cambridge, v. 93, n. 1, 1978, p. 43. 
por adequadamente definidos, não se ressentindo de grande esforço exegético, deixando menos espaço para interpretação constitucional no quetoca à delimitação do seu conteúdo. Mesmo nestas hipóteses, questionamentos relacionados à efetividade dos direitos podem subsistir, uma vez que a aplicação em concreto destas mesmas cláusulas constitucionais pode estar sujeita a graduações.

Sistemas de comon law assumem como premissa que adjudicação é um componente relevante no desenvolvimento do conteúdo dos direitos. A intervenção legislativa não é descartada como necessária, mas pode ser restringida no que toca ao seu leque de possibilidades. Sistemas de civil law, ao contrário, privilegiam as escolhas legislativas, reservando a função jurisdicional para o exercício do controle da fidelidade a estas mesmas opções. A adjudicação, no que toca ao reconhecimento do direito em si, apresenta-se como uma aplicação pretensamente subsuntiva de parâmetros legais ou regulatórios previamente existentes. $O$ conteúdo da determinação judicial pode ser visto como uma suposta derivação dos referidos parâmetros expressos estabelecidos pela lei.

A indicação destas dicotomias (analítico e sintético; civil law e comon law) está altamente simplificada - mas não afeta a proclamação de que esses dois componentes influenciam a natureza da atividade jurisdicional a ser desenvolvida, especialmente quando o direito em discussão é de cariz social.

O binômio constituição analítica e civil law induz à conclusão de que os elementos normativos se tem todos por presentes, configurando perfeitamente direitos cuja violação possa ser restaurada por uma simples intervenção judicial retificadora. Duas concepções teóricas explicam e apoiam esta mesma percepção: o essencialismo dos direitos e o tailoring principle.

\section{ESSENCIALISMO DOS DIREITOS}

A aproximação teórica que situa no essencialismo dos direitos o componente mais relevante do binômio direito-ação é descrita por Levinson ${ }^{15}$ como uma 15 LEVINSON, Daryl J. Rights Essentialism and Remedial Equilibration. 1999. Columbia Law Review, New York, v. 99, n. 4, 1999, p. 857-940. 
teorização cunhada pelos constitucionalistas, de natureza descritiva e prescritiva em relação ao modo de desenvolvimento da atividade adjudicativa, em particular no judicial review.

Uma advertência preliminar é de se fazer em relação aos riscos associados à tradução da expressão americana rights essentialism - componente central da categoria sob exame. $O$ sentido literal de essencialismo envolve a crença de que exista um conjunto de atributos ou categorias que faça das coisas o que elas são, e que a tarefa da ciência e da filosofia seja a sua descoberta e expressão. A transposição desse conceito para associá-lo a direitos reconhecidos no exercício da jurisdição constitucional envolve admitir o reconhecimento de que esses mesmos direitos sejam atributos essenciais daquela ordem constitucional; do conjunto de valores que o Texto Fundamental expressa. A relação de essencialidade, portanto, se estabelece entre direito (a ser reconhecido e proclamado) e constituição, de onde se crê que ele emane.

A concepção que preconiza o essencialismo dos direitos assume como premissa um processo de adjudicação que se inicia com a identificação judicial do que expresse valores puramente constitucionais. ${ }^{16}$ A proclamação em si da existência em si de um direito, nesta abordagem, será o resultado da interpretação constitucional a partir de seus principais compromissos valorativos. Estes direitos, extraídos diretamente da constituição, devem ter a si reconhecido um status especial, que culminará por constringir possíveis intervenções legislativas que possam, de alguma maneira, ameaçá-los na sua substância.

O essencialismo dos direitos busca identificar um direito em estado puro, que emerge dos valores constitucionais e é também informado pela sua possível articulação com todo o sistema que emerge da constituição. O esforço interpretativo que extrai da constituição como sistema, um determinado direito, deve se desenvolver sem a contaminação da noção operacional de uma possível providência adjudicativa que o assegure, entendida esta última tão somente como uma fórmula operativa para a implementação dos direitos de sede constitucional, que previne ou pune a sua violação. ${ }^{17}$ Essa dissociação entre 16 LEVINSON, Daryl J. Rights Essentialism and Remedial Equilibration, p. 858.

17 LEVINSON, Daryl J. Rights Essentialism and Remedial Equilibration, p. 861. 
direito e prestação jurisdicional que o protege é uma simples consequência da distinção essencial entre uma proclamação que descreve um ideal corporificado na constituição, e a tradução desse mesmo ideal num standard operacional para a solução de conflitos específicos. Sentido e aplicação são aspectos distintos quando se cogita de análise preceitual, e eles devem ser mantidos separados, de modo a prevenir-se a contaminação do primeiro pelo último. Tratar aos direitos em ambiente apartado supostamente contribui para incrementar sua relevância pela sua associação com valores constitucionais, distanciando-se de contingências factuais que necessariamente interferem na delimitação de uma resposta adjudicativa consistente. ${ }^{18}$

Proclamação de direitos e resposta judicial à sua alegada violação são duas fases distintas de um mesmo processo social de outorga de sentida a valores constitucionais. Segundo a perspectiva de $\mathrm{Fiss}^{19}{ }^{19}$, tem-se na primeira fase os direitos operando em nível abstrato; e na segunda, o provimento jurisdicional que o assegura no mundo prático. Uma vez identificado o verdadeiro valor constitucional inerente a um determinado direito, esse mesmo conteúdo é transferido para o aparato jurisdicional que "traduz o direito numa regra operacional aplicada aos fatos do mundo real". ${ }^{20}$

A perspectiva do essencialismo é influenciada por outras preocupações, quando se cuida de adjudicação constitucional - especialmente, aquelas atinentes à legitimação, e à adesão de parte do legislativo com os resultados decorrentes da judicial review. Interpretação constitucional no seu extremo (reconhecendo um direito diretamente a partir do seu texto) deve ser reservada às Cortes, e a implementação desse mesmo direito no campo operacional é um dever orientado ao Parlamento - o que é inteiramente compatível com o papel institucional de cada qual dos braços de poder político.

É de se ter em conta que o essencialismo dos direitos é intensamente criticado como fundado numa separação artificial entre direitos e sua asseguração jurisdicional, disjunção que pode minar aos primeiros. A interdependência 18 LEVINSON, Daryl J. Rights Essentialism and Remedial Equilibration, p. 934.

19 FISS, Owen M. The Supreme Court, Term. Foreword: The Forms of Justice, p. 52.

20 LEVINSON, Daryl J. Rights Essentialism and Remedial Equilibration, p. 858. 
entre direitos e a resposta adjudicativa que os assegura (dizem os críticos do essencialismo) são uma consideração instintiva formulada pelo julgador, e negála contribui tão somente para ocultar essa operação intelectual. No campo em especial dos direitos sociais, a separação entre direitos e prestação jurisdicional ignora a inegável circunstância de que os recursos são finitos ${ }^{21}$; de que os direitos sociais concorrem entre si, e que escolhas alocativas vão necessariamente acontecer no estágio de sua implementação.

A aproximação afinada com o essencialismo dos direitos, não obstante concebida num ambiente normativo de constituição sintética, pode ser perfeitamente transposta para o cenário de carta analítica que se tem no Brasil. Não obstante a vasta lista de direito humanos incorporada ao texto constitucional, muitos deles são referidos de modo genérico, possivelmente como reflexo de uma teorização insuficiente acerca de seus objetivos e contornos. $O$ direito à moradia é um exemplo claro de uma cláusula constitucional muito sintética, referido que é no art. $6^{\circ}$, caput da Carta Federal - sem nenhum outro preceito que dele cogite. Diante dessa indeterminação, a busca dos componentes do direito que se repute constitua sua essência, é atividade jurisdicional que segue pertinente e exigível.

Tribunais brasileiros, quando explorando o conteúdo do direito fundamental à moradia, por exemplo, normalmente irão associá-lo à dignidade humana como uma premissa indispensável à adjudicação. Essa é uma clara tentativa de transformar a proteção à moradia numa expressão daqueles valores públicos, referidos na concepção do essencialismo dos direitos. O problema é que relacionar direito à moradia com a proteção à dignidade humana pode ser uma proclamação revestida de impacto retórico - mas não contribui de fato, no incremento da compreensão acerca do conteúdo ou propósito deste mesmo direito. Todos os direitos humanos são direcionados a esse mesmo resultado, e a preservação da dignidade humana é uma diretiva - mas não pode ser vista como um critério objetivo que permita adequada definição da cláusula constitucional.

Também é possível explicar essa inclinação alinhada com o essencialismo dos direitos, expressa especificamente pelas duas Cortes Superiores brasileiras 21 JEFFRIES JR., John C. The Right-Remedy Gap in Constitutional Law, p. 105. 
a partir da premissa de que elas não se devem dedicar à análise de matéria de fato. Isso proporciona um natural apartamento de considerações operacionais, desconectadas que são da "pureza" da missão de encontrar-se o direito em debate. A presunção de que a fase de implementação seja um resultado direto do reconhecimento do direito havido no estágio anterior permite, de outro lado, transferir a definição da resposta adjudicativa de execução para as Cortes inferiores, o que pode se revelar estrategicamente atraente para as Cortes Superiores.

O efeito mais evidente do essencialismo dos direitos é a ênfase na dimensão normativa, e a despreocupação com o viés operativo, que se tem como automático, ou quando menos, sabido. O provimento afirma o direito e pouco se preocupa com as estratégias adequadas à sua restauração, seja no que toca às partes diretamente envolvidas na demanda, e mais ainda no que respeita ao plano macro de aplicação e efetividade desse direito.

Não só o essencialismo dos direitos se infiltra na visão que a jurisdição tem de seu papel; também a lógica do tailoring principle oculta a complexidade da delegação relação direito-provimento.

\section{“TAILORING PRINCIPLE"}

A expressão tailoring, com o sentido de aderência, adequação, de algo que é feito sob medida, é aplicada no cenário norte-americano no tema da adjudicação em diversas circunstâncias. Alude-se a tailoring como consectário da premissa de que a cada direito deve corresponder uma ação, agora traduzida como uma relação necessariamente próxima entre o resultado desta mesma ação, e a superação da violação a direito. A resposta jurisdicional deve se relacionar com a violação como uma medida corretiva, que busque alcançar um resultado sob medida, a saber, eliminar os efeitos danosos da transgressão. ${ }^{22}$ Esse acoplamento perfeito entre lesão a direito e resposta adjudicativa se tem por atributo prévio do sistema judicial - as respostas ajustadas já existem, e a adjudicação simplesmente seleciona a que é própria àquela situação.

22 GEWIRTZ, P. Choice in the transition: School desegregation and the corrective ideal. Columbia Law Review, New York, v. 86, N. 4, May 1986, p.732. 
O tailoring principle pode ser visto como uma tentativa de reforçar a sindicabilidade judicial, garantindo que sempre existirá uma resposta jurisdicional específica e supostamente efetiva aos reclamos de violação a direito. Também pode ser entendido como meio para reduzir a discricionariedade judicial quando se tenha em jogo a preservação de cláusulas constitucionais sensíveis como a do devido processo e da igualdade. Posiciona-se, portanto, a proposta do tailoring principle após a ideia do essencialismo. Isso porque não mais se discute a mecânica de identificação do direito em si e de seus componentes; o que se tem agora é a pretensão de perfeito acoplamento entre uma lesão a direito e a resposta institucional devida.

De maneira a reforçar esses resultados positivos, o tailoring principle deve ser entendido como a proclamação de uma relação direta e causal entre a violação em si ao direito, e a resposta judicial traduzida em provimento. O foco deve concentrar-se na análise da violação ao direito, e uma vez delimitada esta mesma violação como premissa factual e legal, identificar o provimento judicial apropriado à hipótese será uma operação objetiva e dedutiva. Adjudicação, conforme esse entendimento, está inescapavelmente direcionada à promoção da máxima reparação do direito.

Esta suposta relação causal é muito criticada por Fiss $^{23}$, que a qualifica como formalista, resultando no esvaziamento do direito sub análise. A conexão direta entre provimento jurisdicional e direito violado é vista como enganosa, presumindo a delimitação da fonte da "violação" do direito como uma possibilidade sempre presente. Essa presunção não se sustenta, especialmente no âmbito dos direitos sociais, onde são variados os fatores que conduzem à vitimização do reclamante, a maior parte deles se situando fora do âmbito possível de controle pela corte. ${ }^{24}$

Os componentes mais relevantes do tailoring principle, segundo Fiss" ${ }^{25}$, são: "(a) a violação ao direito é vista como a exclusiva origem do provimento a ser outorgado; (b) cada cláusula específica do provimento outorgado só é compreensível a partir da violação a direito que se quer corrigir; (c) presume-se que é possível 23 FISS, Owen M. The Supreme Court, Term. Foreword: The Forms of Justice, p. 46-50.

24 SHANE, Peter M. Rights, Remedies and Restraint, Chicago-Kent Law Review, Chicago, v. 64, n. 2, 1988, p. 555.

25 FISS, Owen M. The Supreme Court, Term. Foreword: The Forms of Justice, p. 47. 
a delimitação de um singular, específico, único provimento - da mesma forma que há uma única solução para um silogismo; e (d) o provimento, assim como a conclusão do silogismo, é visto como consequência da violação, resultado esse extraído com alto grau de certeza." Estas qualidades - exclusividade, especificidade absoluta, singularidade e certeza - não estarão presentes em um contexto de uma intervenção judicial estruturante. Esta objeção pode ser claramente reproduzida no que se refere à adjudicação de direitos socioeconômicos, em que mesmo a decisão havida em demanda individual se revela, a rigor, estruturante, à medida em que interfere na configuração das políticas públicas que promovem a sua efetividade.

A última objeção refere-se ao manejo da afirmada relação causal e direta como uma cortina de fumaça em relação ao verdadeiro critério de escolha da espécie de resposta jurisdicional ofertada, que muitas vezes se fundamenta, a rigor, na visão pessoal do julgador acerca do objeto da decisão.

O tailoring principle também é criticado por Chayes, fundado numa longa série de decisões nas quais o objetivo de controle da discricionariedade judicial não foi atingido. ${ }^{26} \mathrm{~A}$ falta de aptidão para obtenção dos resultados pretendidos deveria, segundo o autor, ser suficiente para descartar um princípio que pode impor limites sobre as possíveis respostas adjudicativas.

Não obstante as críticas anteriormente apontadas, a proposição de uma relação de perfeito acoplamento entre uma violação a direito e a resposta jurisdicional correspondente ainda encontra defensores. Segundo Shane ${ }^{27}$, o tailoring principle não proíbe a consideração de outros efeitos além da restauração direta dos direitos na criação da moldura de solução, preservando uma margem de discricionariedade no desenho da resposta judicial que se reputa necessária. Para admitir-se, essa abertura sem abdicar-se do tailoring principle, bastaria distinguir entre o objetivo da prestação jurisdicional requerida e os termos em que ela venha a ser afinal exarada. Ter-se-ia no primeiro o resultado reputado devido pelo autor observado o tailoring; e no segundo (provimento efetivamente outorgado), a possível imposição de condições ao réu as quais exijam medidas distintas daquelas reputadas devidas pelo autor.

26 CHAYES, A. Foreword: Public law litigation and the Burger Court, Harvard Law Review, Cambridge, v. 96, n. 4, 1982, p. 46.

27 SHANE, Peter M. Rights, Remedies and Restraint, p. 554. 
Há um claro traço de "determinismo" no tailoring principle, transformando o conteúdo do provimento jurisdicional numa decisão de segunda linha na adjudicação, de inspiração meramente instrumental. Esta aproximação parece inadequada num cenário em que a "interpretação principiológica dos direitos conduziu a uma expansão de seu escopo, de tal modo que direitos nem sempre podem ser simplesmente traduzidos em provimentos convencionalmente

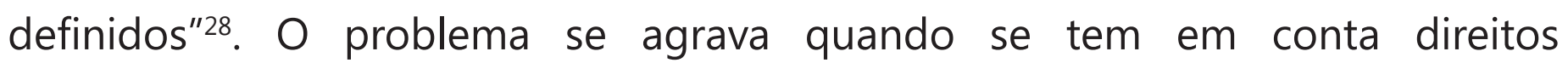
socioeconômicos, nos quais a violação frequentemente causa lesão em duas dimensões distintas: 1) na esfera de direitos do autor; e 2) no objetivo mais amplo de mudança social implícito em qualquer deles.

A aplicação do tailoring principle nas demandas envolvendo direitos socioeconômicos irá envolver ao menos a premissa de que o controle jurisdicional deve ocorrer em espectro mais estrito. Afinal, a violação de direitos que provocou o litígio e figura como elemento chave do desenho da resposta jurisdicional é normalmente individual, inspirada por uma percepção subjetiva de que o Judiciário esteja mais inclinado à procedência na demanda individual do que na coletiva. ${ }^{29}$ Assim sendo, a adjudicação irá ocorrer no mais das vezes em soluções restaurativas e compensatórias. Isto pode não se adequar a objetivo maior de implementação de direitos socioeconômicos, os quais, em essência, buscam trazer transformação e inclusão social; um resultado que visa ao futuro.

O segundo resultado negativo possível da aplicação do tailoring principle aos pleitos de direitos socioeconômicos é o descarte da interdependência que é típica dos direitos humanos como um todo. Isto pode acontecer em duas perspectivas distintas: 1) considerando o dilema da contraposição inerente entre individual e coletivo no que se refere a um específico direito em debate; e 2) considerando a concorrência possível entre direitos socioeconômicos distintos, seja em demandas individuais, ou mesmo em ações coletivas.

28 SHANE, Peter M. Rights, Remedies and Restraint, p. 554.

29 HOFFMANN, Florian; BENTES, Fernando R. N. Accountability for Social and Economic Rights in Brazil. In.: GAURI, VARUN; BRINKS, D. M. (Eds.). Courting social justice: judicial enforcement of social and economic rights in the developing world. Cambridge: Cambridge University Press, 2008, pp. 100-145 e GRINOVER, Ada Pelegrini, The Collective Actions Held Hostage by the Authoritarianism, Panorama of Brazilian Law, Juiz de Fora, v. 1, 2013, p. 85-99. 
Enfatizar os supostos traços corretivos de um provimento predeterminado por uma violação desconsidera a necessária atenção imanente às preocupações com justiça à teoria de justiça, que é de ser associada à proteção dos direitos socioeconômicos. ${ }^{30}$ A satisfação individual irá prevalecer numa perspectiva de justiça puramente compensatória, e as consequências sistêmicas como "furar filas", e a apropriação indevida do discurso dos direitos humanos pelos mais favorecidos será ignorada, sepultando o potencial de materialização de justiça distributiva.

A relação estrita pretendida pelo tailoring principle entre o conteúdo de provimentos previamente conhecidos e sua aptidão para superar a violação debatida no processo causa também uma aproximação reducionista no que se refere à possível inter-relação entre direitos humanos compreendidos na moldura normativa aplicável. Restaurar plenamente o sujeito num conflito envolvendo o direito à moradia, por exemplo, pode se refletir em seu próprio direito à vida e à segurança (quando se cuide de desocupação de área de risco); ou o direito a um meio ambiente adequado (quando a edificação está inserida numa área de proteção ambiental). A adjudicação deverá, verdadeiramente, deixar de se caracterizar numa prática restaurativa, para converter-se num trade-off entre lesões.

A par disso, as características associadas à relação entre direitos e provimentos, preconizadas pelo tailoring principle (exclusividade, completa especificidade, singularidade e certeza), exigem uma moldura legal provida de determinação no que se refere ao direito em questão que não é usual, nem mesmo desejável no que se refere aos direitos socioeconômicos.

Indeterminação é uma característica associada ao direito de uma maneira geral, e isso afasta a adjudicação da pretensa fundamentação da existência de um liame dedutivo entre norma e provimento assecuratório dos seus efeitos. ${ }^{31}$ No campo dos direitos humanos, incerteza está geralmente presente, e isso não é um defeito; é uma exigência de permanente justificação do direito em si mesmo. O objetivo dos direitos humanos é por definição "um direito dinâmico, fluido,

30 WALDRON, Jeremy. Socioeconomic Rights and Theories of Justice (NYU School of Law, Public Law Research Paper n. 10-79, 2010). Disponível em: http://papers.ssrn.com/sol3/ papers.cfm?abstract_id=1699898. Acesso em: $1^{0}$ de dezembro de 2015.

31 KRESS, K. Legal indeterminacy. California Law Review, California, v. 77, n. 2, 1989, p. 283-337. 
sempre aberto a novos mecanismos de direitos para a expansão do crescimento humano". ${ }^{32}$ Entretanto, mesmo de acordo com a lógica de soluções "sob medida" preconizadas pelo tailoring principle, se o ponto de partida (o direito em debate) não se caracterizar como certo, específico e singular no que se refere ao seu âmbito de proteção, não terá a vocação para prover a mesma certeza especificidade e singularidade na definição do provimento.

A principal consequência da exclusão do princípio da solução sob medida como uma ferramenta possível na adjudicação dos direitos socioeconômicos está na exigência de justificação - não acerca do direito em si, porque é desnecessária ante a sua incorporação numa cláusula constitucional expressa; mas a justificação na definição do provimento. Ainda assim, podem surgir objeções quanto à adequação institucional do judiciário como espaço adequado para promover escolhas arbitrárias entre as diversas alternativas possíveis de implementação deste mesmo direito.

\section{EFEITOS DELETÉRIOS DA SUBVALORIZAÇÃO DA DELIMITAÇÃO}

DO PROVIMENTO

O essencialismo dos direitos e o princípio da solução sob medida trazem um resultado similar no que se refere à relação com as espécies de provimento jurisdicional vocacionado à proteção ao direito: ambos proclamam que o segundo é uma simples consequência do primeiro, predeterminada pelo direito identificado no conflito. A definição do conteúdo do provimento de procedência seria uma simples transposição de componentes encontradas nos direitos, e deverá se ajustar como a única resposta possível à violação capaz de restaurar a posição jurídica devida ou antes titularizada pelo autor. Estas ideias parecem deslocadas no que se refere ao litígio envolvendo direitos socioeconômicos.

Reconduzir o autor a uma posição jurídica que lhe seja devida - como pretende o tailoring principle 33 - é um objetivo associado com uma perspectiva de justiça

32 GEARTY, C. Against Judicial Enforcement. In.: ; MANTOUVALOU, V. Debating social rights, Oxford and Portland, Oregon: Bloomsbury Publishing, 2010, p. 18.

33 A expressão comumente utilizada pela doutrina norte-americana é turn the subject whole. 
corretiva que se refere principalmente à superação de uma lesão havida antes do litígio. ${ }^{34}$ Justiça corretiva busca esclarecer a causa e visa à recomposição da posição jurídica subjetiva antes detida. ${ }^{35}$ Já desigualdade e exclusão social são realidades a serem modificadas, independentemente da apuração de causas e imputação de responsabilidades. Direitos socioeconômicos devem lidar com esta visão retrospectiva, mas são principalmente orientados à garantia prospectiva de um bem social ou serviço reconhecido necessário num nível consensual de bemestar que a sociedade firmou.

A premissa da violação retrospectiva, determinante da providência de justiça corretiva, exige o reconhecimento de uma conduta errônea ${ }^{36}$, voltada ao passado, e essa compreensão no que se refere aos direitos socioeconômicos será duplamente falha. Primeiro, porque se sustenta na proposição de que sempre haverá o perpetrador do dano; e no que se refere à violação dos direitos humanos, este sendo frequentemente identificado com o Estado lato sensu. ${ }^{37}$ Em segundo lugar, a demanda fundada em direitos sociais expressaria necessariamente um juízo de desvalor em relação a uma errônea configuração do conteúdo do direito como reconhecido pelo Estado. Nenhuma destas assertivas está completamente correta.

A ideia de que no campo dos direitos fundamentais se tenha sempre vítimas, selvagens e salvadores já foi criticada como um estereótipo que oculta comodamente o fato de que as ações estatais em verdade, em boa parte, refletem a sociedade na qual se operam. ${ }^{38} \mathrm{~A}$ par disso, a exclusão social raramente pode estar associada a uma única causa ou agente. No que toca à segunda premissa, um pleito judicial envolvendo direitos socioeconômicos pode estar traduzindo não um reprocho às anteriores escolhas, mas simplesmente uma pretensão de incrementar o âmbito de proteção que se tem até então reconhecido em $34 \mathrm{ROACH}$, Kent. The Limits of Corrective Justice and the Potential of Equity in Constitutional Remedies, Arizona Law Review, Tucson, v. 33, 1991, p. 861.

$35 \mathrm{ROACH}$, Kent. The Limits of Corrective Justice and the Potential of Equity in Constitutional Remedies, p. 864.

$36 \mathrm{ROACH}$, Kent. The Limits of Corrective Justice and the Potential of Equity in Constitutional Remedies, p. 867.

37 MUTUA, Makau W. Savages, victims, and saviors: the metaphor of human rights, Harvard International Law Journal, Cambridge, v. 42, n1, winter 2001, p. 201-245.

38 MUTUA, Makau W. Savages, victims, and saviors: the metaphor of human rights, p. 202. 
decorrência de mudanças sociais, econômicas ou tecnológicas. Não se cuidaria, portanto, de "corrigir a violação", mas de avançar numa pauta política de incremento no grau de efetividade do referido direito. ${ }^{39}$

Violação e restauração como matrizes de explicação da intervenção judicial no que se refere aos direitos socioeconômicos podem ser um binômio a expressar uma perspectiva reducionista. Ela desconsidera o principal objetivo de promover a igualdade. A decisão judicial assecuratória de direitos sociais numa perspectiva estrutural não é [puramente] terminativa, ou transferência compensatória, mas um esforço para rever um programa buscando futuras consequências de uma forma que acomode o espectro de interesses envolvidos. ${ }^{40}$ Prevenir a frustração da tutela numa perspectiva macro de direitos socioeconômicos pode ser, de fato, mais relevante para alcançar o objetivo constitucional de transformação social do que uma sentença puramente restaurativa.

Uma segunda objeção se dirige à pretensão de especificidade e singularidade de um provimento judicial associado a esta perspectiva causal e dedutiva. Esta é uma compreensão que pressupõe um perfeito alinhamento entre direitos e resposta jurisdicional protetiva - o que no domínio dos direitos constitucionais é muito controvertido. ${ }^{41}$ Vagueza nas cláusulas constitucionais deferindo direitos socioeconômicos torna quase impossível a caracterização de uma relação causal e generalizada entre a violação de certo direito e uma específica e única resposta judicial que se repute adequada. A solução não irá apoiar-se numa definição formal (e numa possível cristalização) do conteúdo do direito, mas numa compreensão ampla da função do provimento jurisdicional que o assegura, que deve transcender o mero "dar a cada um o que é seu" e comprometer-se com o projeto macro de superação de desigualdades.

A "certeza" quanto ao conteúdo do provimento, identificável dedutivamente a partir de uma alegada violação de direitos, é também enganosa porque resulta

39 VALLE, Vanice Regina Lírio. Demandas derivadas e ampliação do núcleo essencial do direito à moradia: deferência como critério judicial de solução. In.: VIEIRA, J. R.; CARMAGI, M.M.L.; SGANZERLA, R.B. (Org.). Direitos fundamentais e jurisdição constitucional. Belo Horizonte: Editora Fórum, 2016, p. 182-208.

40 CHAYES, A. The role of the judge in public law litigation, Harvard Law Review, Cambridge, v. 89, n. 7, 1975-1976, p. 1294.

41 JEFFRIES JR., John C. The Right-Remedy Gap in Constitutional Law, p. 87-88. 
em reduzir o ônus de fundamentação. Este é um aspecto sensível porque pode induzir o Judiciário a uma postura conservadora, inclinada à simples repetição de fórmulas já utilizadas nas primeiras demandas na matéria, naquilo que Levinson denomina provimentos dissuasórios. ${ }^{42}$ Isto também poderá autorizar a simples transferência dos aspectos operacionais do cumprimento da ordem para as cortes inferiores em sede de execução de sentença, ou mesmo para os braços legislativo ou executivo do poder. Esta pode se revelar uma estratégia confortável ao Judiciário, que proclamando uma alegada dependência objetiva entre o direito debatido e a resposta judicial se vê desonerado de apreciações consequencialistas. Por outro lado, especialmente nos casos de decisões contramajoritárias, essa transferência de poder pode resultar, de fato, na negativa da proteção judicial adequada ao direito violado - já que os poderes majoritários vencidos podem simplesmente resistir, ainda que passivamente ao cumprimento da decisão. ${ }^{43}$

A suposta relação objetiva e causal entre os direitos violados e o provimento adequado é sujeita a outra crítica. Considerando que os próprios direitos têm conteúdo indeterminado, identificar a relevância jurídica ou, como nas considerações acima, o desvio de conduta numa situação de fato ou decorrente do comportamento do administrador será em si uma tarefa difícil. Num cenário de indeterminação, a violação à juridicidade decorrente de uma má compreensão da realidade ou da ordem jurídica pode acontecer não como uma recusa proposital de observância de seus deveres constitucionais, mas por força de uma má compreensão que seja esperada de um servidor público, ou do que o sistema normativo efetivamente exija. ${ }^{44}$

O poder de comunicação da mensagem constitucional enunciadora de um direito depende de três principais características: a habilidade do transmissor de capturar a atenção respeitosa do administrador; a amplitude e a força da mensagem; e a sua clareza ou ausência de distorção no entendimento. Ainda que a captura do foco de atenção respeitosa do administrador possa ser presumida quando a mensagem se origina numa cláusula constitucional expressa ante a 42 LEVINSON, Daryl J. Rights Essentialism and Remedial Equilibration, p. 884-885.

43 FRIEDMAND, Barry. When Rights Encounter Reality: Enforcing Federal Remedies. South California Law Review, Los Angeles, v. 65, 1991, p. 738.

44 SCHUCK, P.H. Suing government: citizens remedies for official wrongs. New Haven: Yale University Press, 1983, p. 4. 
supremacia do referido documento normativo, o mesmo não pode ser afirmado no que se refere à amplitude e à clareza dessa mesma mensagem. Indeterminação dos direitos irá enfraquecer esta compreensão inabalável dos deveres públicos que devem surgir da cláusula constitucional sub judice. À mingua do amplo alcance da mensagem e de sua clareza, o surgimento de novas compreensões dos deveres dos administradores públicos será provável - e a dissonância tende a aumentar nas organizações públicas, enquanto a mensagem (parcial) circula pela burocracia acumulando erronias compreensivas.

Essa é a razão pela qual mesmo a identificação de lesões ao direito e sua qualificação como resultante de condutas errôneas da Administração não são por si mesmo autoevidentes. Examinar a inobservância constitucional nesse tema exigirá contextualização para compreender o comportamento do administrador; para determinar a existência de um ato repreensível, e mesmo para afirmar adequadamente a existência de lesão ao requerente. Tudo isso quebra a suposta relação meramente dedutiva e evidencia o imperativo de uma cunhagem do provimento jurisdicional que dialogue especificamente com as nuances do contorno do direito que o litígio revela.

O essencialismo dos direitos ou o tailoring principle podem se apresentar como um mecanismo explicativo do modo de definição da prestação jurisdicional a ser ofertada, a evitar o enfrentamento das dificuldades inerentes em estabelecer a reação correta em face de uma afirmada violação de direitos, mas certamente não são suficientes para superar os desafios impostos à sua efetiva tutela judicial. Embora o discurso do essencialismo dos direitos sugira um redirecionamento das atenções para a definição do seu conteúdo que não fora conferido pela cláusula constitucional em si; promover a sua eficácia não é uma operação que possa ser realizada exclusivamente num nível abstrato.

O que parece errado com o essencialismo dos direitos ou com o tailoring principle, especialmente no campo dos direitos socioeconômicos, está em ignorar o seu principal objetivo, que é produzir efeitos num mundo real falho e confuso. "Adjudicação constitucional é funcional, não apenas no nível dos provimentos mas em toda a estrutura acima". ${ }^{5}$ Direitos socioeconômicos são instrumentais para a

45 LEVINSON, Daryl J. Rights Essentialism and Remedial Equilibration, p. 873, tradução livre da autora. 
promoção do desenvolvimento humano, não são menos funcionais. Provimentos jurisdicionais empoderadores de direitos socioeconômicos deveriam ter o poder de superar as falhas, prover a adesão aos propósitos futuros de sua realização, e mesmo persuadir os "devedores" a manter o mesmo nível de compromisso, seja em relação aos requerentes, seja de toda a sociedade. Tudo isso deveria ser alcançado numa realidade por vezes resistente. Segundo Starr, "Cortes não podem decidir pretensões no vácuo, elas precisam criar um direito concretizável no mundo real" . ${ }^{46}$ Esses resultados não podem ser alcançados pensando-se direitos socioeconômicos de forma isolada do nível de concretização. Mesmo que se admitisse que a essencialidade do direito se opera pela transferência (e não pela negativa) do dever de estruturação de um conjunto adequado de políticas públicas, regulamentação e legislação por uma outra instituição que não o Judiciário; mais uma vez, o resultado poderá ser o empobrecimento da dimensão do conteúdo operativo do provimento que descuraria do seu necessário papel no aperfeiçoamento da prática institucional. Afinal, por vezes, a própria violação dos direitos que gerou a demanda judicial está relacionada à inércia administrativa ou legislativa em promover a deliberação que agora, pela via jurisdicional, estaria sendo restituída a essas mesmas instituições. Se as verdadeiras razões para o bloqueio institucional que produziram a mencionada inércia não forem adequadamente atacadas, a decisão judicial não produzirá qualquer resultado concreto no mundo real. Também é possível que a violação dos direitos tenha sido causada por uma compreensão equívoca do respectivo conteúdo, ou sobre o critério mínimo a ser atingido para que o direito seja adequadamente protegido mediante deliberação governamental. Essencialidade do direito pode ampliar a compreensão do conteúdo do direito e dos deveres estatais na sua proteção - porém, mais uma vez, eles não podem ser vistos de forma abstrata. A melhor forma de reforçar continuamente a eficácia dos direitos socioeconômicos é manter uma relação dinâmica entre as demandas, as decisões judiciais e os seus resultados no mundo da vida.

\section{CONSIDERAÇÕES FINAIS}

A análise acima permite afirmar que essencialidade dos direitos ou tailoring principle não são a resposta correta, porque partem de premissa falsa, que se 46 STARR, Sonja B. Rethinking 'Effective Remedies': Remedial Deterrence in International Courts, New York University Law Review, New York, v. 83, n. 3, June 2008, p. 738. 
sustenta na afirmação de que o principal problema a superar é a indeterminação do conteúdo dos direitos, e de que sua tutela jurisdicional será intensificada com a delimitação de um padrão em abstrato.

Incerteza acerca do conteúdo dos direitos sociais e a abertura para o debate quanto ao seu conteúdo em especial é um elemento constitutivo da própria teoria dos direitos humanos ${ }^{47}$; é uma característica que garante a sua evolução como uma tarefa permanente para os intérpretes e administradores públicos. A verdadeira falha na proposta constitucional pode residir na circunstância de que o fenômeno, em alguma maneira previsível, de violação dos direitos socioeconômicos, se vê desacompanhado de uma estrutura institucional adequada à correção de rumos na perspectiva estrutural - e não no debate individual, caso a caso.

Não obstante o quadro traçado, fato é que a judicialização segue como possibilidade em nosso sistema constitucional, e o postulado do non liquet segue exigindo do magistrado a oferta de resposta ao conflito. O desafio teórico repousa em como otimizar a oferta de jurisdição nesse contexto.

A desmistificação do essencialismo dos direitos e do tailoring principle parece uma primeira etapa necessária ao aperfeiçoamento da jurisdição. Isso importará em resgatar a ideia da necessária resposta individualizada a cada conflito, tendo em conta, no que toca ao provimento jurisdicional a ser ofertado, não um cardápio em abstrato de respostas previamente desenhadas, mas a especificidade do caso em exame.

É certo que esta proposição estará em rota de colisão com o fenômeno do litígio de massa, que empurra a outorga da prestação jurisdicional para as duas lógicas aqui criticadas. Esse conflito, todavia, é de ser enfrentado o quanto antes, eis que se tem na própria curva ascendente dos litígios de massa a evidência mais clara da ineficácia da judicialização como resposta às violações a direitos sociais.

Segunda etapa necessária ao aprimoramento da atividade jurisdicional parece estar na clara delimitação do conteúdo da ordem judicial expendida. Fórmulas 47 SEN, Amartya. Elements of a Theory of Human Rights. Philosophy \& Public Affairs, Princeton, 32:4, 2004,p. 323. Ver também OREND, Brian. Justifying Socioeconomic Rights, in HOWARD-HESSMANN, Rhoda E. e WELCH JR., Claude E. Economic rights in Canada and the United States, USA: University of Pennsylvania Press, 2006, p. 25-40. 
genéricas como a condenação ilíquida ou a aplicação indiscriminada do regime de responsabilidade solidária aos entes políticos favorece o não cumprimento pela vagueza do comando. $O$ quadro se agrava no que toca à não proteção efetiva do direito em debate, quando essa fórmula genérica, sob clara inspiração do tailoring principle se afigura como "a" resposta - específica, única e certa - à violação daquele direto, e passa a ser repetida acriticamente nas demais demandas.

Último ponto de observação diz respeito ao indispensável resgate da relevância da fase de execução de sentença - único momento do processo que permitirá aferir a eficácia do provimento como outorgado. Esse deveria ser o momento de maior aprendizagem no ciclo do controle judicial - e o que se vê, ao contrário, é a subvalorização desta etapa. A realização da justiça não se dá na enunciação da sentença, mas na sua execução, voluntária ou forçada. No campo dos direitos sociais em especial, só na execução da sentença se poderá aferir o impacto do provimento outorgado na vida do jurisdicionado e no funcionamento das instituições.

Estes são os novos desafios propostos por uma compreensão substantiva do que seja o acesso à justiça, especialmente no campo dos direitos sociais. A curva sempre crescente das demandas não é um sinal de triunfo do Judiciário; ela é sinal de que a judicialização segue retroalimentada como canal de veiculação dos conflitos sociais. A incessante multiplicação dos litígios é a prova cabal de que se viram - acadêmicos, profissionais do direitos e julgadores - falhando em nosso dever de servir aos intentos transformadores da Carta da Cidadã, e ao seu compromisso com a justiça social.

\section{REFERÊNCIAS DAS FONTES CITADAS}

BRASIL. Supremo Tribunal Federal. ARE 745745 AgR, Relator(a): Min. CELSO DE MELLO, Segunda Turma, julgado em 02/12/2014, PROCESSO ELETRÔNICO DJe-250 DIVULG 18-122014 PUBLIC 19-12-2014) (Braz.).

BRASIL. Supremo Tribunal Federal. ARE 745745 AgR, Relator(a): Min. CELSO DE MELLO, Segunda Turma, julgado em 02/12/2014, PROCESSO ELETRÔNICO DJe-250 DIVULG 18-122014 PUBLIC 19-12-2014) (Braz.).

CHAYES, A. The role of the judge in public law litigation, Harvard Law Review, Cambridge, v. 89, n. 7, 1975-1976, p. 1281-1316. 
CHAYES, A. Foreword: Public law litigation and the Burger Court, Harvard Law Review, Cambridge, v. 96, n. 4, 1982, p. 4-60.

DIXON, Rosalind; GINSBURG, Tom Deciding Not to Decide: Deferral in Constitutional Design, International Journal of Constitutional Law, New York, v. 9, n. 3-4, outubro 2011, p. 636-672.

FIELDS, A. B. Human rights theory: criteria, boundaries, and complexities. International Review of Qualitative Research, California, 2, 2009, p. 407-418.

FISS, Owen M. The Supreme Court, Term. Foreword: The Forms of Justice, 1979 Harvard Law Review, Cambridge, v. 93, n. 1, 1978, p. 1-58.

FRIEDMAND, Barry. When Rights Encounter Reality: Enforcing Federal Remedies. South California Law Review, Los Angeles, v. 65, 1991, P. 735-780.

GARCÍA-VILLEGAS, Mauricio. Law as Hope: Constitutions, Courts, and Social Change in Latin America, Wisconsin International Law Journal, Madison, v. 20, n. 2, 2001-2002, p. 353-370.

GEARTY, C. Against Judicial Enforcement. In.: ; MANTOUVALOU, V. Debating social rights, Oxford and Portland, Oregon: Bloomsbury Publishing, 2010, 201 p.

GEWIRTZ, P. Choice in the transition: School desegregation and the corrective ideal. Columbia Law Review, New York, v. 86, N. 4, May 1986, p.728-798.

GRINOVER, A.P. The Collective Actions Held Hostage by the Authoritarianism, Panorama of Brazilian Law, Juiz de Fora, 1, 2013, p. 85-99.

HOFFMANN, Florian; BENTES, Fernando R. N. Accountability for Social and Economic Rights in Brazil. In.: GAURI; VARUN; BRINKS, D. M. (Eds.). Courting social justice: judicial enforcement of social and economic rights in the developing world. Cambridge: Cambridge University Press, 2008, pp. 100-145.

JEFFRIES JR., John C. The Right-Remedy Gap in Constitutional Law, Yale Law Journal, New Haven, v. 109, n.1, p. 87-114.

JUNG, Courtney; HIRSCHL, Ran; ROSEVEAR, Evan; Economic and Social Rights in National Constitutions. American Journal of Comparative Law, Ann Arbor, Michigan, v. 62, n. 4, p. 1043-1094, 2014.

KENNEDY, D., International Human Rights Movement: Part of the Problem?, Harvard Human Rights Journal, Cambridge, v. 15, p. 101-125, 2002.

KRESS, K. Legal indeterminacy, California Law Review. California, v. 77, n. 2, 1989, p. 283-337. 
LIEBENBERG, S. Socio-economic rights: adjudication under a transformative constitution, Cape Town: Juta and Company Ltd, 2010, p. 141.

LEVINSON, Daryl J., Rights Essentialism and Remedial Equilibration. 1999 Columbia Law Review, New York, v. 99, n. 4, 1999, p. 857-940.

LIEBENBERG, S. Socio-economic rights: adjudication under a transformative constitution, Cape Town: Juta and Company Ltd, 2010, 542 p.

LIU, Goodwin. Rethinking Constitutional Welfare Rights, Stanford Law Review, Stanford, v. 61, n. 2, April 2010, p. 203-270.

MAESTAD, O.; RAKNE L.; FERRAZ O. L. M. F. Assessing the Impact of Health Rights Litigation: a Comparative Analysis of Argentina, Brazil, Colombia, Costa Rica, India, and South Africa. In.: YAMIN, A.; GLOPPEN, S. Litigating health rights. Can courts bring more justice to health? Cambridge: Harvard University Press, 2011, p. 445.

MUTUA, Makau W, Savages, victims, and saviors: the metaphor of human rights, Harvard International Law Journal, Cambridge, v. 42, n1, winter 2001, p. 201-245.

OREND, Brian, Justifying Socioeconomic Rights. In.: HOWARD-HESSMANN, Rhoda E.; WELCH JR., Claude E. Economic rights in Canada and the United States, USA: University of Pennsylvania Press, 2006, p. 25-40.

ROACH, Kent. The Limits of Corrective Justice and the Potential of Equity in Constitutional Remedies, Arizona Law Review, Tucson, v. 33, 1991, p. 859-905.

SCHEINGOLD, Stuart A. The politics of rights: lawyers, public policy and political change. USA: Yale University Press, 1974, 224p.

SCHEPPELE, Kim Lane. Aspirational and Aversive Constitutionalism: The Case for Studying Crossconstitutional Influence Through Negative Models, International Journal of Constitutional Law, New York, v. 1, n.2, 2003, p. 296-324.

SCHUCK, P.H. Suing government: citizens remedies for official wrongs. New Haven: Yale University Press, 1983, 262 p.

SEN, Amartya, Elements of a Theory of Human Rights, Philosophy \& Public Affairs, Princeton, 32:4, 2004, p. 315-356.

SHANE, Peter M. Rights, Remedies and Restraint, Chicago-Kent Law Review, Chicago, v. 64, n. 2, 1988, p. 531-572. 
STARR, SONJA B. Rethinking 'Effective Remedies': Remedial Deterrence in International Courts, New York University Law Review, New York, v. 83, n. 3, June 2008, p. 693-768.

SUNSTEIN, Cass. Acordos constitucionais sem teorias constitucionais. Revista de Direito Administrativo, v. 246, Rio de Janeiro, 2007, p.79-94.

VALLE, Vanice Regina Lírio. O papel da adjudicação como mecanismo social de composição de conflitos. In.: CÂMARA, Alexandre Freitas, PIRES, Adilson e MARÇAL, Thais (Org.). Estudos de Direito Administrativo em Homenagem ao Professor Jessé Torres Pereira Junior. Belo Horizonte: Editora Fórum, 2016, p. 371-387.

VALLE, Vanice Regina Lírio. Demandas derivadas e ampliação do núcleo essencial do direito à moradia: deferência como critério judicial de solução. In.: VIEIRA, J.R.,; CARMAGI, M.M.L.; SGANZERLA, R.B. (Org.). Direitos fundamentais e jurisdição constitucional. Belo Horizonte: Editora Fórum, 2016, p. 182-208.

VIEIRA, Oscar Vilhena, Do compromisso maximizador ao constitucionalismo resiliente. In.: DIMOULIS, D. [et al.]. Resiliência constitucional: compromisso maximizador, consensualismo política e desenvolvimento gradual. São Paulo: Direito GV, 2013, p. 18-24.

WALDRON, Jeremy, Socioeconomic Rights and Theories of Justice (NYU School of Law, Public Law Research Paper n. 10-79, 2010). Disponível em: http://papers.ssrn.com/sol3/papers. cfm?abstract_id=1699898. Acesso em: $1^{\circ}$ de dezembro de 2015.

YOUNG, Katharine. Freedom, Want and Economic and Social Rights: Frame and Law. Mariland Journal of International Law, Maryland, v. 24, n. 1, 2009, p. 182-208.

Recebido em: fev/2017

Aprovado em: abr/2017 